\title{
Formaçáo de Professores para a Educação Especial: uma Discussáo Sobre os Modelos Brasileiro E Italiano ${ }^{1}$ \\ Special Education Teacher Preparation: a Discussion of Brazilian and ITALIAN MODELS
}

\author{
Márcia GREGUOL ${ }^{2}$ \\ Erica GOBBI ${ }^{3}$ \\ Attilio CARRARO ${ }^{4}$
}

RESUMO: com os recentes avanços legislativos no sentido da massificação da inclusão de alunos com necessidades educacionais especiais nas escolas regulares, emergem discussôes sobre as mudanças requeridas na formação de docentes para o atendimento desta nova demanda. O objetivo deste estudo foi discutir os modelos brasileiro e italiano de formaçáo de professores para atuar na educação especial. Para tanto, foi realizada uma pesquisa documental, analisando textos legais de ambos os países que versassem sobre o tema. A Itália foi o primeiro país na Europa a promover o fim das escolas especiais e a inclusão de todos os alunos com deficiência nas escolas regulares. Ainda neste país, nota-se que as diretrizes governamentais são claras com relação à capacitação de professores para atuar com alunos com necessidades educacionais especiais. Por outro lado no Brasil, embora tenham ocorrido grandes avanços no que se refere à legislaçáo que sustenta a formação docente, ainda existe uma carência de parâmetros mais específicos sobre os conteúdos mínimos necessários para que os professores tenham maiores subsídios para promover a inclusão com qualidade.

PALAVRAS-CHAVE: Educação Especial. Formação de Professores. Inclusão.

\begin{abstract}
As public policies advance in the direction of mass producing inclusion of special educational needs students in regular schools, discussions have emerged about changes that are required in teacher preparation to meet this new demand. The aim of this study was to discuss Brazilian and Italian models of teacher preparation for those working in special education. To this end, we conducted a documentary study, analyzing legal texts related to the topic from both countries. Italy was the first country in Europe to promote the end of special schools and the inclusion of all students with disabilities in regular schools. Furthermore, in this country there are clear government guidelines regarding teacher preparation to work with students with special educational needs. On the other hand in Brazil, despite the great advances regarding public policies that support teacher preparation, specific parameters on the minimum content necessary for providing teachers with the subsidies they need to promote quality inclusion are still lacking.
\end{abstract}

KEYWORDS: Special Education. Teacher Preparation. Inclusion

\section{INTRODUÇáo}

Os desafios impostos diante da inclusão de alunos com necessidades educacionais especiais no ensino regular têm sido foco de discussóes em diversos segmentos. Embora existam

\footnotetext{
${ }^{1}$ Apoio financeiro: Ciência sem Fronteiras - CNPq

${ }^{2}$ Universidade Estadual de Londrina - Centro de Educação Física e Esporte. Endereço: Rodovia Celso Garcia Cid, Campus Universitário, 86057-970, Londrina - PR Paraná, Brasil. mgreguol@gmail.com

${ }^{3}$ Università degli Studi di Padova. Endereço:Palazzo del Capitanio Piazza Capitaniato, 3, 35139, Padova, Itália. ericagobbi@libero. it

${ }^{4}$ Università degli Studi di Padova - Palazzo. Endereço: del Capitanio Piazza Capitaniato, 3, 35139, Padova, Itália. attilio.carraro@unipd.it
} 
divergentes opiniôes a respeito da melhor forma de aplicação prática da proposta, é inegável que seu sucesso está intimamente ligado à capacitação adequada de recursos humanos para a atuação com a diversidade. $\mathrm{O}$ crescente número de alunos com necessidades educacionais especiais matriculados na rede regular de ensino brasileira é um indicador positivo, porém isoladamente não é um fato tranquilizador, uma vez que se sabe que de um modo geral ainda existe uma grande carência de espaços, materiais e informaçóes adequados para oferecer a esta população experiências de aprendizagem de fato positivas.

MITTLER (2003) considera que a inclusão não diz respeito a colocar as crianças nas escolas regulares, mas a mudar as escolas para torná-las mais responsivas às necessidades de todas as crianças; diz respeito a ajudar todos os professores a aceitarem a responsabilidade quanto à aprendizagem de todas as crianças nas suas escolas e prepará-los para ensinar aquelas que estáo atualmente excluídas por qualquer razão.

Ainda que a legislação brasileira apresente uma série de garantias no que concerne à inclusão de jovens com necessidades educacionais especiais no ensino regular (BRASIL, 1996; BRASIL, 2001a), a aplicação prática de tais medidas ainda esbarra na falta de recursos e na dificuldade do professor em lidar com estes alunos em sala de aula. Referindo-se especificamente à capacitação de professores, alguns avanços podem ser observados, como a iniciativa da Secretaria de Educação Continuada, Alfabetização, Diversidade e Inclusão (SECADI) de implementar políticas nacionais de apoio à formação continuada de docentes, sobretudo na modalidade à distância (MEC, 2012). Embora tais medidas sejam de grande importância, no entanto, não conseguem sanar o déficit formativo dos professores. Além disso, poucas medidas têm sido de fato tomadas para amenizar o descompasso entre a formação inicial de docentes e as questóes de ordem prática desencadeadas com a inclusão escolar.

Nos países europeus, diferentes abordagens vêm sendo utilizadas no que tange à inclusão escolar (AGÊNCIA ..., 2009). Destaque especial pode ser feito à Itália, país no qual as escolas especiais foram extintas na década de 1970, sendo todos os alunos nesta oportunidade encaminhados para a escola regular (SANCHES; TEODORO, 2006). Ainda que existam questóes de ordem práticas a serem superadas, o modelo italiano de capacitação de professores é visto como uma referência pela sua ação inovadora e traz à tona pontos que podem ser de grande interesse para a realidade brasileira.

Desenvolvido predominantemente por meio do ensino público, o modelo escolar italiano apresenta características particulares que o diferenciam do modelo brasileiro, como, por exemplo, o fato de agregar num mesmo espaço alunos provenientes de níveis socioeconômicos diversos e, em muitos casos, de origens étnicas distintas. Essa condição presente pode ser considerada um ponto que favorece a maior tolerância à diversidade. Além disso, existe uma série de dispositivos legais que favorecem a inclusão escolar na Itália, tais como a previsão de um docente de apoio em casos necessários, número reduzido de alunos e a formação de um professor que seja capaz de realizar um planejamento individualizado, que náo busque fazer com que todos os alunos atinjam o mesmo rendimento, mas sim que valorize as potencialidades de cada um (MONTEIRO, 2003).

Cabe ressaltar uma diferença no que diz respeito aos aspectos conceituais na educação especial entre Brasil e Itália. Enquanto no primeiro país são considerados alunos 
com necessidades educacionais especiais aqueles que apresentem alguma deficiência, transtorno global do desenvolvimento ou altas habilidades, no segundo esta denominação é dirigida apenas àqueles com deficiência. Daí porque, proporcionalmente, o número de alunos elegíveis para esta modalidade de ensino na Itália seja significativamente menor (CABRAL, 2010).

No Brasil, existe uma forte corrente que apoia a inserção total dos alunos com necessidades educacionais especiais na rede regular de ensino, como acontece no sistema escolar italiano. No entanto, os críticos desta proposta sustentam que a capacitação precária dos professores seria um ponto que fatalmente a levaria ao fracasso. Dessa forma, a compreensão de diferentes modelos de formação docente pode contribuir para o levantamento de questóes que levem ao aprimoramento de nossas práticas, bem como a observação de experiências que já foram capazes de revelar resultados positivos.

Tendo em vista a relevância e iminência do tema, este estudo se propóe a discutir os modelos, brasileiro e italiano de formação de professores, para atuar na educação especial, buscando ressaltar pontos de congruência e divergência, assim como possíveis aspectos a serem aprimorados.

\section{Desenvolvimento}

\subsection{ASPECTOS HISTÓRICOS DA INCLUSÁO ESCOLAR NO BRASIL}

A ideia da inclusão surgiu em oposição à prática da exclusão social a que foram submetidos os indivíduos com deficiências durante muitos séculos. Essa exclusão ocorria de forma total, ou seja, todos os considerados "deficientes" eram estigmatizados como inválidos e julgados como inúteis à vida em sociedade.

Para MANTOAN (2003), a educação especial no Brasil se estruturou segundo modelos assistencialistas e segregativos e pela segmentação das deficiências, contribuindo para que a educação de jovens com necessidades especiais acontecesse em um "mundo à parte". A autora destaca que a educação especial no nosso país teve início no século XIX, inspirada em modelos norte-americanos e europeus, na forma de açóes isoladas e não governamentais. $\mathrm{O}$ modelo inicialmente proposto era baseado em conceitos médicos.

MAZZOTA (2003) divide a história da educação para crianças com deficiências em três fases:

- Fase assistencialista: na qual se julgava necessário proteger os jovens com deficiência do mundo, colocando-os em instituiçóes privadas de forte caráter assistencialista;

- Fase da educação especial de caráter médico-terapêutico: na qual surgiram as primeiras obras sobre as deficiências e as primeiras instituiçôes especializadas de caráter médicoterapêutico;

- Fase da integração: que compreendeu dois momentos:

- Intervenção centrada no aluno

- Intervenção centrada na escola 
$\mathrm{Na}$ intervenção centrada no aluno, as crianças eram agrupadas em categorias, segundo um diagnóstico. $\mathrm{O}$ apoio era prestado em salas específicas, de modo a não causar qualquer perturbação na sala regular. Já na intervenção centrada na escola, passa a caber a esta a responsabilidade de responder à individualidade e às necessidades educativas especiais de cada criança.

CORREIA (1997) também ressalta alguns momentos históricos. O autor analisa que no inicio do século XX, crianças com deficiências passaram a ser rotuladas e isoladas em "instituiçóes especiais". Em uma segunda fase, algumas escolas públicas começaram a aceitar certa responsabilidade na educação de parte destas crianças, porém de forma segregada, marginalizando-as em "classes especiais". Nascia em seguida o conceito da "educação integrada", baseando-se no conceito de normalização, no qual a escola utilizaria os aspectos mais favoráveis do meio para o desenvolvimento da criança com deficiência. Em um momento mais recente surge a ideia da inclusão, na qual, segundo o autor, atende-se o aluno com necessidades educacionais especiais na classe regular, adaptando-se serviços para que estes atinjam todas as crianças.

Rodrigues (2003) destaca que a escola tradicional, valorizando a homogeneidade, obrigava que todos os alunos se adaptassem às exigências do sistema. Propondo um ensino igual para todos, a escola marginalizava aqueles que aparecessem como diferentes. Já na lógica da heterogeneidade, ao contrário, as diferenças constituem a base para a construção de uma inovadora abordagem pedagógica.

Em 1994, a Conferência Mundial da UNESCO sobre Necessidades Educacionais Especiais deixou claro que a exclusão nas escolas incentiva a discriminação, que a educação é questão de direitos humanos e que os indivíduos com deficiências deviam frequentar as escolas, cabendo a elas modificarem-se para incluir a todos (SILVA; LLERENNA JÚNIOR; CARDOSO, 2002). A partir de então, com a aprovação da Declaração de Salamanca, diversos esforços começaram a ser movidos no sentido de tornar real o movimento de inclusão escolar no Brasil e em todo mundo. No entanto, logo foi possível constatar que a inclusão bemsucedida de alunos com deficiências ou outras necessidades educacionais especiais demandaria um sistema educacional diferente do então disponível.

Após a assinatura da Declaração de Salamanca em 1994, o Brasil atravessou um momento de grandes revisóes na área do atendimento a crianças com deficiências e uma das maiores discussóes disse respeito à formação dos professores. No entendimento de alguns educadores, não seria necessário formar professores especializados no ensino para crianças com deficiências, já que esta tarefa passaria a ser de todos os professores, em vista do movimento de inclusão.

Para Baumel e Castro (2002), a principal ideia da Declaração de Salamanca foi sua "orientação inclusivista", considerando que as escolas regulares, ao atingirem a educação para todos, devem ser o ponto de partida para a criação de comunidades solidárias e de uma sociedade que seja capaz de incluir. Nesse novo conceito, a escola, ao invés de encarar as diferenças como dificuldades, considera-as como oportunidades para a criação de um ambiente educativo mais rico para todos. 
Em 2001 foi aprovado o decreto 3956 (BRASIL, 2001b) que estabeleceu as normas firmadas pelo governo brasileiro na Convenção Interamericana para Eliminação de Todas as Formas de Discriminação Contra as Pessoas Portadoras de Deficiência, realizada na Guatemala em 1999. Neste documento coloca-se que deve ser oferecido tratamento igualitário às pessoas com deficiência no que se refere aos seus direitos e liberdades fundamentais. A aprovação da Declaração de Salamanca e da Convenção de Guatemala estimulou uma profunda mudança na legislação brasileira, que passou a primar pelo direito de acesso à escola regular. Tal premissa repercutiu diretamente na forma como se pensava a capacitação de professores, que, até aquele momento, era focada sobretudo na especialização de docentes interessados em trabalhar no segmento da educação especial. A partir deste momento, passou a ser necessário que todos os professores fossem preparados para atuar com a diversidade, necessidade esta que ainda impóe grande desafio para os cursos de formação inicial e continuada.

Apesar da necessidade de mudanças, no entanto, os avanços legislativos até 2005 foram relativamente tímidos no que se referiu à formação docente. Destaca-se no ano de 2003 a portaria 3284 do Ministério da Educação (MEC, 2003), que dispôs sobre importantes critérios de acessibilidade para que pessoas com deficiência pudessem ingressar no ensino superior, fazendo emergir em diversas universidades brasileiras discussóes mais aprofundadas sobre a falta de capacitação dos professores para atuar com esta nova demanda.

\subsection{MODELO BRASILEIRO DE FORMAÇÃO DE PROFESSORES PARA A EDUCAÇÃO ESPECIAL}

Ao serem considerados os alunos com necessidades educacionais especiais, estima-se que no Brasil atualmente existam em torno de 2.500.000 em idade escolar (4 aos 17 anos), sendo que destes menos de um milhão frequentam regularmente uma escola (INEP, 2012). Desta forma, o número de alunos com necessidades educacionais especiais matriculados atualmente nas escolas representaria $1,7 \%$ do número total de alunos existentes. Dados do Ministério da Educação também dão conta que, a partir de 2008, houve uma mudança no perfil de procura por escolas entre alunos com necessidades educacionais especiais, com a maior parte das matrículas sendo realizadas em escolas regulares (MEC, 2012).

Os números expostos no último senso escolar (INEP, 2012) reforçam a urgência da melhora da formação de professores em nosso país. Aproximadamente $80 \%$ dos alunos com necessidades educacionais especiais estão matriculados na rede pública de ensino. Foi possível observar um crescimento no número total de matrículas de alunos com necessidades educacionais especiais entre os anos de 2011 e 2012, de 584.124 para 628.768 (uma variação de 7,6\%). Os dados também mostraram que mais de meio milhão de alunos com necessidades especiais estavam matriculados no ensino fundamental, um avanço de $7,7 \%$ com relação ao ano anterior. $\mathrm{O}$ maior crescimento no número de matrículas deste sistema, porém, deu-se no ensino médio, representando um aumento de 24,9\%. Os números do Instituto Nacional de Estudos e Pesquisas Educacionais (INEP) revelaram, desta forma, que os alunos com necessidades educacionais especiais estão atingindo séries mais elevadas de ensino, o que na teoria é um dado positivo, embora seja preciso analisar o nível real de formação desenvolvido.

Os objetivos do governo federal brasileiro são ambiciosos no sentido da inclusão nas escolas regulares. O Plano Nacional dos Direitos da Pessoa com Deficiência - o Viver 
sem Limite, lançado em 2011 (MEC, 2011) estabelece a meta de aumentar o número de matrículas de alunos com deficiência no ensino regular. Para que tal meta seja atingida com êxito, no entanto, ajustes ainda devem ser feitos no que tange à formação de professores aptos a receber estes estudantes e a lidar com as questóes relacionadas à diversidade em sala de aula. De fato é possível notar que muito se evoluiu no que diz respeito à legislação brasileira que trata sobre o assunto. Especialmente a partir dos anos 1980 começaram a se intensificar as discussões no Brasil sobre a necessidade de mudanças nos cursos de formação de professores (VITALIANO, 2007), que deveriam em seus currículos abordar conteúdos que permitissem vivências de situaçóes práticas do contexto de trabalho, inclusive no que diz respeito aos alunos com necessidades educacionais especiais (BAUMEL, 2004). O foco da discussão, que ainda atualmente é um desafio a ser superado, trata de como sintonizar os conteúdos teóricos e práticos da formação docente com as necessidades que se apresentam. A lacuna existente entre a formação e a atuação prática tem feito com que os professores sintam-se perdidos diante da missão de lidar com a diversidade em sala de aula, sobretudo pela falta de conhecimento sobre como adaptar as atividades, materiais, conteúdos programáticos e procedimentos de ensino.

$\mathrm{O}$ advento da inclusão escolar sem dúvida desencadeou importantes modificações na forma de se pensar a formação docente. Até o início da década de 1990, trabalhar com alunos com necessidades especiais era uma realidade próxima quase exclusivamente para aqueles professores que atuavam nas escolas ou associaçóes que prestavam atendimento específico aos jovens com deficiência ou transtornos do desenvolvimento. Com as mudanças na legislação, no entanto, todos os professores passaram a dar atendimento a estes alunos, ainda que tenha ocorrido grande descompasso entre a reforma legal e a revisão do sistema de capacitação docente para colocá-la em prática (MICHELS, 2006). De fato, muitos cursos de formação docente no Brasil nem sequer apresentam em seu currículo conteúdos especificamente relacionados à inclusão escolar (RINALDI, REALI e DA COSTA, 2007) e, quando estes estão presentes, ainda é possível observar forte influência do modelo médico-psicológico, que rotula os alunos e os classifica de acordo com uma abordagem meramente técnica (OMOTE, 2004).

Um grande avanço legal no sentido da inclusão de alunos com necessidades educacionais especiais na escola foi a promulgação em 1996 do novo texto da Lei de Diretrizes e Bases da Educação Nacional - LDBEN (BRASIL, 1996), que pela primeira vez na história do país, reservou um capítulo exclusivamente para o tratamento da educação especial. Entre outros pontos, a lei definiu que todos os professores de classes regulares ou especiais devem receber especialização adequada para lidar com todos os alunos, visando sempre que possível a inclusão em salas comuns. Segundo Souza e Silva (1997), o grande avanço da nova LDBEN em relação à anterior foi a inserção de temas antes só tratados em decretos, portarias ou normas.

O Plano Nacional de Educação - PNE (BRASIL, 2001a), ao analisar a situação da educação especial no Brasil, propôs uma série de diretrizes e ações progressivas para a melhora do atendimento educacional para as pessoas com necessidades educacionais especiais. Segundo o PNE, essa política deveria abranger o âmbito social, reconhecendo todas as pessoas como cidadãos e o âmbito educacional, tanto nos aspectos administrativos (adaptação dos espaços e equipamentos), como na qualificação de professores e de todos os demais profissionais envolvidos, garantindo vagas no ensino regular para os diversos tipos de condiçóes. Entre outras açóes, são colocadas as necessidades de se organizar em todos os municípios parcerias com as áreas de 
saúde e assistência, além do oferecimento de recursos materiais adequados para a aprendizagem de alunos com necessidades especiais, da adaptação estrutural dos estabelecimentos de ensino a fim de facilitar o acesso de todos à escola, do aumento da quantidade da verba destinada para o propósito da inclusão nas escolas e do preparo contínuo dos professores para lidar de forma cada vez mais efetiva com esta nova realidade.

O repensar sobre a formação docente ganhou nova perspectiva em 2009 (BRASIL, 2009) com a aprovação do Plano Nacional de Formação de Professores da Educação Básica (PARFOR), proposto para atender à exigência legal da formação mínima necessária para todos os professores. Tal plano, que articula as instituições públicas de ensino superior e as secretarias estaduais e municipais de educação, busca concretizar as açóes do Plano de Metas Compromisso Todos pela Educação (PDE), objetivando que todos os docentes atuantes na educação básica tenham acesso a um curso de nível superior. De acordo com o PARFOR, o docente que ainda não possua a formação inicial mínima exigida poderá graduar-se na primeira licenciatura, na segunda licenciatura (neste caso para aqueles que atuem fora da sua área de formação), ou ainda poderá obter formação pedagógica (neste caso para aqueles com formação em bacharelado, mas sem licenciatura), na modalidade presencial ou à distância. Para os docentes que já possuam a formação exigida são oferecidos cursos à distância de aperfeiçoamento e especialização em diversas áreas, entre os quais o curso na área de educação especial, pensado prioritariamente para professores que atuem em salas de recursos multifuncionais (MEC, 2012). Apesar desta iniciativa emergencial, que se propôs a sanar a ausência da formação pedagógica que atinge cerca de 30\% dos professores brasileiros, alguns problemas já puderam ser rapidamente observados. Além do diálogo por vezes insuficiente entre as esferas federal, estadual e municipal do poder, a pouca observância da possibilidade de aplicação prática dos conteúdos desenvolvidos nos cursos é apontada como ponto negativo. Destaca-se ainda que a baixa remuneração oferecida aos professores torna a carreira docente pouco atrativa no Brasil e faz com que pessoas muitas vezes mal preparadas atuem no segmento. Dessa forma, ainda persiste o desafio do governo de oferecer melhor capacitação aos docentes atuantes na educação básica.

No entanto, cabe ressaltar que a formação dos futuros professores, e não apenas daqueles já atuantes, também deve ser discutida. Voltando-se especificamente à educação especial, observa-se a necessidade que sejam estabelecidas diretrizes claras nos cursos de pedagogia e licenciaturas sobre os conteúdos mínimos a serem oferecidos, de modo que sejam formados professores com habilidades para lidar com a inclusão da diversidade na sala de aula. Além da inserção de disciplinas que abordem as questóes da educação especial, uma alternativa interessante para enfatizar o vínculo com a atividade prática seria que algumas disciplinas dos cursos, que tradicionalmente tratam apenas dos alunos ditos "normais", também incluíssem no seu corpo de conteúdos aspectos relacionados aos alunos com necessidades educacionais especiais.

A primeira iniciativa no sentido de inclusão de conteúdos veio em 1994, por meio do da Portaria 1793 do Ministério da Educação (BRASIL, 1994), que recomendava que os cursos de Pedagogia e todas as licenciaturas inserissem nas suas grades ao menos uma disciplina que abordasse a inclusão de alunos com necessidades educacionais especiais. Talvez por se tratar apenas de uma recomendação, entretanto, o fato é que muitos cursos não incluíram a referida disciplina, mostrando que a Portaria isoladamente seria insuficiente para garantir tal mudança. 
Nas Diretrizes Curriculares Nacionais para a Formação de Professores na Educação Básica (CNE, 2002) é destacado que as instituiçóes de ensino superior devem formar professores aptos a lidar com as questóes da diversidade na escola. Mais especificamente no sexto artigo, as Diretrizes deixam clara a importância de conteúdos que contemplem os alunos com necessidades educacionais especiais. No entanto, apesar de serem feitas recomendaçóes relevantes, novamente não são colocadas orientaçôes claras sobre a obrigatoriedade da inserção de conteúdos. Ainda em 2002, com a promulgação da lei 10.436 (BRASIL, 2002), tornouse obrigatória a inclusão nos cursos de formação de professores uma disciplina que abordasse o ensino da Língua Brasileira de Sinais (LIBRAS). Tal inserção, embora tenha representado certo avanço, ainda mostra-se insuficiente, pois, embora os egressos dos cursos de Pedagogia e Licenciaturas tenham noçóes básicas sobre LIBRAS, isso não garante que possuam conhecimento suficiente para efetivamente incluir o aluno surdo.

Analisando-se as Diretrizes Curriculares Nacionais para os cursos de Pedagogia e para as diversas licenciaturas (CNE, 2002; VITALIANO; DALL'ACQUA, 2012), novamente é possível evidenciar a falta de especificidade no que se refere aos conteúdos exigidos referentes à inclusão de alunos com necessidades educacionais especiais. De fato, chama a atenção, especialmente nos cursos de licenciatura, como praticamente nada é mencionado sobre a educação especial. Um curso que se destaca é a licenciatura em Educação Física, que pontua em suas diretrizes a necessidade da formaçáo de um professor com conhecimentos sobre as especificidades de pessoas com deficiência. Nas demais, nada é mencionado pontualmente sobre a preparação do profissional para atuar com alunos com necessidades educacionais especiais. Para o curso de Pedagogia, embora fosse plausível esperar direcionamentos mais detalhados no sentido do ensino inclusivo, comenta-se apenas de maneira ampla a importância de se formar professores com conhecimentos sobre alunos com necessidades educacionais especiais, porém sem fazer menção específica sobre os direcionamentos para que essa meta seja atingida.

Novamente, a falta de orientaçóes claras sobre disciplinas, estágios e conteúdos mínimos sugeridos faz com que as diretrizes de certa forma pouco contribuam no sentido de aprimorar a formação docente no contexto da inclusão escolar. Talvez essa falta de especificidade seja uma das explicaçóes para o fato já mencionado anteriormente de que muitos cursos no Brasil ainda não apresentem nem ao menos uma disciplina que aborde conteúdos relacionados ao tema.

Ainda tratando da questão, as Diretrizes Nacionais para a Educação Especial na Educação Básica (BRASIL, 2001c) enfatizam dois perfis distintos de professores atuantes nas escolas: o professor de classe comum capacitado para atender alunos com necessidades educacionais especiais e o professor especializado em educação especial. O professor especializado, compreendido como aquele que presta o Atendimento Educacional Especializado aos alunos com necessidades especiais nas salas de recursos ou estabelecimentos especiais de ensino, deve possuir formação que o habilite a atuar na educação especial. Também neste caso não é totalmente clara qual será esta formação comprovada, que pode variar desde uma graduação específica até cursos de aperfeiçoamento ou especialização na área. Algumas instituiçóes de ensino superior no Brasil já estão oferecendo a graduação específica em Educação Especial na modalidade presencial e à distância, além de diversos cursos de especialização neste sentido. No entanto, é preciso lembrar que também o professor de classe comum deve ter em sua formação 
inicial conteúdos mínimos para promover a inclusão escolar, sobretudo porque na prática, em boa parte dos casos, será ele o agente responsável por lidar com a diversidade. Ainda que haja a previsão do professor de apoio nas salas de aula em que existam alunos com deficiências mais graves incluídos, geralmente é o próprio professor da sala comum que se vê diante da missão, sem auxílio adicional, de gerir as questões, conflitos e desafios da inclusão de alunos com necessidades educacionais especiais na maioria das escolas. Dessa forma, também neste caso devem ser oferecidos subsídios na formação inicial e continuada mais consistentes do que os atualmente disponíveis, o que reforça a ideia de que se definam orientaçôes mais claras nos cursos de Pedagogia e nas licenciaturas sobre conteúdos e experiências a serem propostos no preparo profissional.

\subsection{Histórico dA EDUCAÇÃo ESPECIAL NA ITÁlia}

Entre os países da Europa, a Itália pode ser considerada pioneira pela sua orientação inclusivista. De fato, muito antes que as discussóes mais aprofundadas sobre a temática aflorassem no continente, o país inovou nos anos de 1970, mais especificamente em 1977, ao promulgar uma lei que aboliu as classes especiais e obrigou a introdução de todos os alunos com deficiência no sistema regular de ensino (SANCHES, 2006).

Os primeiros relatos sobre o que hoje é conhecido como educação especial surgiram em meado dos anos de 1800, quando começaram a surgir as primeiras instituiçóes de ensino para pessoas com deficiência, sobretudo para pessoas com deficiência visual e auditiva, que atuavam de modo basicamente assistencialista e segregado. Este marco histórico é muito semelhante ao que foi observado no Brasil na mesma época. Não obstante, ao se analisar com mais profundidade a evolução histórica da educação especial na Itália, observa-se que o país sempre se mostrou inovador no que se refere à legislação sobre o assunto (CANEVARO; GAUDREAU, 1988). De acordo com Gelati (2004), um personagem que ressalta este fato é Giuseppe Ferrucio Montesano (1868 - 1951), que foi o primeiro a ocupar-se da formação de professores para atuar com pessoas com deficiência, particularmente com deficiência intelectual. Com sua ajuda foi fundada no ano de 1900, em Roma, a Scuola Magistrale Ortofrenica per La Formazione degli Insegnanti per Minorenni Anormali (Escola Magistral Ortofrenica para a formação de Professores para Menores Anormais), primeira escola a focar na formação docente para atuação com alunos com necessidades especiais. Nos anos seguintes a esta iniciativa, seriam abertas escolas com escopo semelhante em diversas outras regiōes da Itália e em outros países europeus. Também Montesano, em 1908, disseminou a ideia de oferecer nas escolas uma opção de salas menos numerosas e com programas simplificados, as chamadas classes diferenciadas. Ainda em 1913, também como resultado de uma iniciativa sua, foi fundada a revista L'assistenza dei minorenni anormali, primeira do gênero que divulgava artigos, para os professores, sobre os métodos de ensino para esta população.

Em 1923, com a Reforma Gentile, o modelo assistencialista de atendimento aos alunos com necessidades educacionais especiais deu lugar a um modelo baseado em seus direitos e necessidades. Assim, entre outras medidas, foi introduzida a obrigatoriedade do ensino para jovens com deficiência visual e auditiva, que deveria ocorrer em institutos especialmente criados para tal finalidade. Além disso, a Reforma determinou a criação de escolas de formação 
para docentes que fossem atuar com tais alunos, o que era uma medida consideravelmente avançada para o pensamento da época (CABRAL, 2010). Apesar do caráter inovador, jovens com outras necessidades educacionais especiais não tinham acesso ainda garantido ao ensino e se acumulavam em classes especiais superlotadas, destinadas àqueles considerados problemáticos por diversas razóes.

Em meados do século XX, a estrutura legislativa italiana começou a acenar para a garantia mais estendida de acesso à educação. A constituição italiana de 1947 (ITALIA, 1947), pouco após o fim da Segunda Guerra Mundial, passa a garantir o direito à educação e à capacitação profissional aos então chamados "inábeis" e "minorados", em um referimento às pessoas com deficiência. Na década de 1960, enquanto em toda a Itália ocorriam grandes manifestaçóes sobre a necessidade de mudança no modelo de ensino de um modo mais abrangente, também se iniciaram discussóes sobre os rumos da educação especial. Associações constituídas por familiares de pessoas com deficiência, como a Associazione Nazionale Famiglie di Fanciulli e Adulti Subnormali (Associação Nacional das Famílias de Crianças e Adultos Subnormais), passaram a reivindicar perante o governo que seus filhos tivessem direito de frequentar uma escola comum (DE ANNA, 2002).

Uma tentativa de mudança do modelo segregado surgiu por meio da lei 118 de 1971, que estabeleceu que os jovens com necessidade educacionais especiais deveriam ser inseridos nas escolas públicas regulares, exceto quando a condição física ou intelectual fosse muito restritiva (GELATI, 2004). No entanto, as escolas não eram preparadas para receber tais alunos e o fato de que estes deveriam se adequar ao processo fez com que ainda continuassem a se multiplicar as escolas especiais. De fato, 1974 foi o ano em que houve maior número de escolas especiais em funcionamento na Itália, ultrapassando 1400 unidades. No ano de 1975, a Comissão Falcucci, reunida com o intuito de discutir a inclusão de jovens com deficiência no ensino regular, elaborou um documento no qual destacava a importância de que as escolas regulares se modificassem para melhor receber estes estudantes, sinalizando a necessidade de revisão do papel da escola especial.

O grande marco da mudança legislativa italiana, no entanto, ocorreu no ano de 1977, com a promulgação da lei 517/1977 (D’ALONZO; IANES, 2007), que tratava da integrazione scolastica nas escolas regulares. O principal avanço proposto pela nova legislação referiu-se à inclusão total dos alunos com necessidades educacionais especiais nas escolas regulares, sendo mantidas apenas algumas escolas especiais para alunos com deficiência auditiva. A fim de oferecer condiçóes para seu pleno cumprimento, a lei trouxe algumas garantias relevantes, tais como o estabelecimento do número máximo de 20 alunos nas classes em que houvesse um aluno com deficiência e a presença de um professor para auxílio, que a partir deste momento não seria mais chamado de professor especializado, mas sim de professor de apoio ou insegnante di sostegno. Ainda sobre o tema, a lei assegura que não poderia ser oferecida uma formação separada que tratasse apenas do assunto da deficiência, mas sim uma especialização dos docentes abordando de maneira mais ampla o tema da diversidade e da inclusão. Outro ponto de destaque é a necessidade de que o aluno fosse incluso em uma escola próxima à sua residência, de modo a facilitar sua sociabilização com o ambiente circundante. Mais tarde, segundo De Anna (2002), o decreto ministerial de 24 de abril de 1986 dispôs sobre a obrigatoriedade da formação especializada para o professor de apoio, com a realização de um curso que formaria 
um profissional apto a contribuir com outros profissionais de modo a facilitar a interação e aprendizagem do aluno com necessidades educacionais especiais.

A demanda crescente de alunos com necessidades educacionais especiais nas escolas italianas motivou a criação de instrumentos legais mais adequados. Assim, em 1992 a lei 104 para a "assistência, integração social e direitos da pessoa com deficiência" propôs, entre outros pontos de avanço, diretrizes mais específicas sobre a formação docente. Especificamente sobre o professor de apoio, a lei esclareceu que este profissional deveria ter um papel de articulação entre o aluno com deficiência e os professores, demais alunos e outros agentes escolares. Além disso, o "apoio" deveria ser entendido de maneira mais ampla, náo restrito apenas ao aluno com deficiência, mas abrangendo também sua família e outras pessoas envolvidas no seu processo de inclusão (GELATI, 2004).

Nas décadas de 1990 e 2000, a Itália, assim como o Brasil, foi signatária de diversos acordos internacionais em prol dos direitos de pessoas com deficiência, inclusive no que diz respeito ao acesso à educação. Dessa forma, foi possível observar também neste país algumas mudanças recentes na legislação de modo a garantir a inclusão mais efetiva de alunos com necessidades educacionais especiais no sistema regular de ensino. Ainda que existam pontos a serem aprimorados, observa-se que, em muitos dos dispositivos legais, a preocupação com a formação docente é evidenciada (DE ANNA, 2007), o que tem repercutido em números positivos no que tange à procura e permanência de alunos com necessidades educacionais especiais nos diversos níveis de ensino.

\subsection{MODELO ITALIANO DE FORMAÇÃo DE PROFESSORES PARA A EDUCAÇÁO ESPECIAL}

Para melhor compreender a formação de professores na Itália, cabe ressaltar algumas particularidades do sistema de ensino daquele país. Até os seis anos completos, ambos os países possuem estruturas semelhantes. $\mathrm{Na}$ Itália, a fase correspondente à educação infantil acontece nas escolas chamadas "maternas", nas quais as crianças permanecem dos três aos cinco anos. A partir deste ponto começam a existir algumas diferenças e o sistema educacional italiano divide-se em três momentos (MIUR, 2010):

- Escola primária (Scuola primaria): com duração de cinco anos, para os jovens aproximadamente dos seis aos 10 anos;

- Escola secundária de primeiro grau (Scuola secondaria di primo grado): com duração de três anos, para jovens aproximadamente dos 11 aos 14 anos;

- Escola secundária de segundo grau (Scuola secondaria di scondo grado): com duração de cinco anos para os alunos que optam em cursar o chamado Liceo (com formação de cunho geral) ou os institutos técnicos ou de três anos para aqueles que optam em realizar um curso profissionalizante. Na primeira opção, o jovem terminaria seus estudos com cerca de19 anos, quando então estaria apto a ingressar em um curso universitário. Já na segunda opção o jovem concluiria seus estudos em torno dos 17 anos e estaria apto a ingressar no mercado profissional ou ainda a cursar mais dois anos no curso profissionalizante, o que o habilitaria também a ascender a um curso universitário. 
Para atuar como professor das escolas materna e primária italiana é necessário frequentar um curso universitário com duração de cinco anos, já inclusas as horas de estágio, chamado Laurea Magistrale in Scienze della Formazione Primaria, por meio do qual o egresso pode ministrar aulas em diferentes áreas de conhecimento. Já para a escola secundária de primeiro e segundo graus, até 2010 o professor devia ter, além da graduação em alguma área do conhecimento específica (Matemática, Química, etc.), um curso de especialização de dois anos, chamado de Scuola di Specializzazione all' Insegnamento Secondario (SSIS). Conforme decreto ministerial de 26 de maio de 1998, em ambas as habilitaçóes, o egresso pode escolher ao final realizar atividades didáticas direcionadas ao atendimento de alunos com necessidades educacionais especiais, de modo a sair também com o diploma de especialização em ensino de apoio ou attività didattica di sostegno (MIUR, 1998).

Com a promulgação do decreto ministerial 249 de 2010 (MIUR, 2010), ocorreram algumas modificaçóes nas exigências para a formação docente. Sem dúvida um grande avanço do decreto de 2010 foi o estabelecimento de conteúdos obrigatórios para os cursos de formação para a escola primária e secundária de primeiro e segundo graus. A partir de então, todos os cursos de formação docente passaram a ter como obrigatória ao menos uma disciplina que tratasse da Didática e Pedagogia Especial. Especialmente para os cursos de formação docente para a escola primária, ganham importância as disciplinas relacionadas ao acolhimento do aluno com deficiência. Outra mudança foi a introdução do Estágio Formativo Ativo ou Tirocinio Formativo Attivo (TFA), seguido por um professo tutor, que passou a ser obrigatório para os docentes da escola secundária em substituição do sistema SSIS, compreendendo ao menos 75 horas dedicadas ao aprimoramento das competências didáticas para a inclusão de alunos com deficiência.

Tratando especificamente da formação do professor de apoio (insegnante di sostegno), o decreto ministerial de 2010 (MIUR, 2010) novamente reforça a importância e o papel deste profissional para a inclusão bem sucedida de alunos com necessidades educacionais especiais e coloca novas exigências mínimas para sua formação. De acordo com o decreto, os egressos dos cursos de formação docente que desejem obter a especialização em ensino de apoio devem cursar ao menos 60 créditos formativos (1500 horas), dos quais 12 (300 horas) são dedicados aos estágios específicos na escola. $\mathrm{O}$ curso de especialização, que prevê uma formação polivalente, deve ser conduzido pelas universidades e o acesso passa a ser obtido por meio de processo seletivo.

De acordo com números de 2012 do Ministério da Instrução, eram 215.590 os alunos com deficiência inclusos nas escolas regulares italianas $(2,3 \%$ do número total de alunos), sendo 91,9\% destes matriculados em escolas públicas. Dos casos de deficiência, a intelectual é apontada como a mais comum, correspondendo a 69,1\% dos casos, seguida da deficiência múltipla $(21,4 \%)$, motora $(4,5 \%)$, auditiva $(3,1 \%)$ e visual $(1,8 \%)$. Ainda dados do referido ministério dão conta que, em 2012, existiam na Itália cerca de 98 mil professores de apoio (12,8\% do número total de professores), o que ainda é considerado um número insuficiente para a demanda das escolas. Para reduzir esta questão problemática, novos cursos de especialização e mestrado têm sido oferecidos pelas universidades, de modo a incentivar a formação de novos professores de apoio, além da oferta de cursos de curta duração para os professores que já se encontram no exercício das suas atividades (MIUR, 2012). 
Um dos dispositivos legais italianos mais recentes sobre a temática da inclusão foi promulgado em dezembro de 2012 (MIUR, 2012) e trata dos instrumentos de intervento para alunos com necessidades educacionais especiais e da organização territorial para a inclusão escolar (Strumenti D'intervento per Alunni con Bisogni Educativi Speciali e Organizzazione Territoriale per L'inclusione Scolastica). Embora ainda existam pontos a serem mais bem elucidados, alguns avanços do decreto ministerial puderam ser claramente percebidos como, por exemplo, a ampliaçáo do conceito de Necessidades Educacionais Especiais, que anteriormente referia-se apenas aos casos de deficiência e, a partir deste decreto, passou a contemplar também os casos de transtornos do desenvolvimento e outros distúrbios da aprendizagem. Outro ponto de destaque do decreto de 2012 foi a regulamentação do funcionamento dos Centros Territoriais de Apoio (Centri Territoriali di Supporto - CTS). Os CTS, espalhados por todo o território italiano, são centros de apoio às escolas, mantidos pelo Ministério da Instrução, e atuam em parceria com os Centros Territoriais para a Inclusão (Centri Territoriali per l'Inclusione - CTI). Enquanto os CTI possuíam a principal função de oferecer serviços de informação sobre serviços locais disponíveis para todos os agentes envolvidos no processo de inclusão escolar (alunos, famílias, professores, dirigentes escolares, entre outros), os CTS destinam-se principalmente a divulgar informaçóes especificamente sobre novos recursos e tecnologias que visam a facilitar a inclusão dos alunos com necessidades educacionais especiais. Além disso, tanto os CTI como os CTS também teriam a função de promover cursos de capacitação docente continuada, abordando temas como novas tecnologias assistivas e serviços de suporte disponíveis.

\subsection{ANÁlISE DOS DOIS MODELOS}

Ao analisar os modelos brasileiro e italiano de inclusão de alunos com necessidades educacionais na escola regular, pode-se observar alguns pontos de congruência. Tanto Brasil como Itália foram signatários de diversas resoluçôes internacionais, como a Declaração de Salamanca e a Convenção de Guatemala, por exemplo, direcionadas a oferecer maiores direitos básicos à cidadania para pessoas com deficiência, entre os quais o acesso irrestrito à educação. Também ambos os países, especialmente a partir da década de 1990, buscaram realizar modificaçóes em sua estrutura legislativa de modo a garantir o acesso de todos à escola regular, tendo a formação docente como uma das preocupaçóes centrais.

No entanto, podem ser percebidas algumas diferenças entre os dois países, a começar pelo conceito daquilo que é chamado de aluno com necessidade educacional especial (NEE). Na Itália, o modelo médico para classificação dos alunos ainda é dominante, o que é demonstrado claramente pela ampla utilização neste país do sistema de Classificação Internacional de Funcionalidade, Incapacidade e Saúde - CIF (WHO, 2001). Embora os decretos mais recentes tentem ampliar este conceito, ainda se pensa a inclusão na Itália quase que totalmente focada para alunos com deficiência. Já no Brasil, o conceito de NEE foi tratado de modo mais amplo, ao menos nos documentos legais, norteando-se primordialmente pelos aspectos educacionais e abrangendo, além daqueles com deficiência, alunos com transtornos do desenvolvimento e aqueles com altas habilidades (MEC, 2007). No entanto, apesar desta diferença teórica, sabe-se que, na prática, ainda existe grande dificuldade no Brasil em se obter orientaçóes claras sobre a formação docente voltada para alunos com altas habilidades ou transtornos do desenvolvimento, e a pouca capacitação que é oferecida aborda quase que exclusivamente o tema da deficiência. 
Outro ponto a ser destacado é que a lei italiana que versa sobre a inclusão é em alguns aspectos mais clara e específica quanto às exigências para garantir um ensino de qualidade para os alunos com necessidades educacionais especiais. Enquanto a lei brasileira faz apontamentos algumas vezes genéricos sobre a formação de professores e a necessidade de recursos materiais e humanos, a legislação italiana expressa claramente quais conteúdos mínimos o aspirante a professor deve ter em seu currículo de formação para poder trabalhar numa escola. Também neste último caso é colocado claramente o número máximo de 20 alunos por turma, além da obrigatoriedade da contratação de um professor de apoio para atuar em salas nas quais tiver um aluno com necessidade educacional especial (GELATI, 2004).

Em todas as suas diretrizes sobre a formação docente, o Ministério da Instrução italiano coloca de modo inequívoco o número mínimo de disciplinas e de horas de estágio específico que abordem a inclusão, tanto para os professores que atuarão na escola primária como na secundária (MIUR, 2013). Ainda que existam críticas ao modelo, como a falta de conexão dos conteúdos teóricos com as situaçôes da prática profissional, certamente as diretrizes obrigam ao menos o oferecimento aos futuros docentes de algum conteúdo que trate do tema. Por outro lado no Brasil, a falta de diretrizes claras que especifiquem conteúdos mínimos nos cursos de licenciatura tem feito com que muitos profissionais cheguem para atuar nas escolas sem ao menos terem tido qualquer tipo de informação sobre as necessidades educacionais especiais.

Ainda outros fatores, como visto ao longo do texto, propiciam um ambiente mais favorável à inclusão na Itália. Entre estes, destacam-se os fatos de, neste país, quase a totalidade das escolas serem públicas, abrangendo alunos de diversos níveis socioeconômicos e etnias, todos os alunos com deficiência obrigatoriamente serem encaminhados para o ensino regular e as dimensóes territoriais serem consideravelmente menores que as do Brasil (CABRAL, 2010). Dessa forma, existe maior facilidade para a uniformização de procedimentos, capacitação continuada e fiscalização por parte do poder público. Também no modelo escolar italiano todos os professores devem ter uma formação universitária de no mínimo cinco anos para exercer a profissão, o que propicia uma base de conhecimentos mais sólida e a possibilidade de realizar estágios em variados campos de atuação antes da obtenção do diploma. Já o Brasil, com uma parte significativa dos professores ainda sem formação universitária, mostra sinais claros de que a capacitação docente tem sido um entrave para a inclusão escolar bem sucedida. Os cursos à distância, oferecidos pelo Ministério da Educação brasileiro como estratégia de curto prazo para elevar o nível de formação dos professores, na prática não se mostram suficientes para oferecer uma base mais sólida de conhecimentos, inclusive no que diz respeito aos alunos com necessidades educacionais especiais (TERRA; GOMES, 2013).

Outro fator que pode ser compreendido como facilitador para a inclusão escolar na Itália, especialmente na escola secundária, é a possibilidade de o aluno optar pelo ensino profissionalizante. Especialmente para os alunos com deficiência intelectual, que talvez não pudessem aproveitar plenamente de todos os conteúdos oferecidos no Liceo ou nos institutos técnicos, a possibilidade de realizar a escola secundária na modalidade profissionalizante permite ao mesmo tempo a conclusão de um nível mais elevado de instrução e a capacitação de curto prazo para o mercado de trabalho (BAPTISTA, 2002). 
Apesar dos pontos positivos, entretanto, algumas críticas vem sendo referidas ao modelo de inclusão escolar italiano, sobretudo nos últimos anos (D’ALONZO; IANES, 2007). Algumas associaçóes de pais e professores na Itália denunciam que em algumas escolas o número máximo de 20 alunos por turma, quando da presença de um aluno com necessidade educacional especial, não tem sido respeitado. Além disso, são apontados também problemas com a acessibilidade arquitetônica de muitas instalações escolares, que em boa parte são acomodadas em prédios antigos, e a carência dos recursos materiais adequados.

O ponto central que se levanta é que barreira legal é apenas a primeira a ser vencida quando se fala em inclusão escolar bem sucedida. De fato a legislação italiana, que já há muito mais tempo discute a inserção total dos alunos na escola regular, apresenta orientaçóes mais específicas no que se refere à formação docente para atuar com alunos com necessidades educacionais especiais. O Brasil, ainda que tenha mostrado uma evidente evolução na última década na legislação neste sentido, possui alguns desafios importantes a serem vencidos, que extrapolam a formação docente para trabalhar com a inclusão, mas que dizem respeito antes de tudo à formação docente de qualidade para atuar na escola.

Neste sentido, acredita-se que a adoção também no Brasil de um professor de apoio e número reduzido de alunos em todas as salas que apresentassem alunos com necessidades educacionais especiais seria um investimento rumo à melhora da qualidade do ensino inclusivo. Não obstante, ressalta-se que a inclusão de disciplinas específicas nos cursos de formação, embora seja de relevância no processo, não é suficiente para sanar todos os déficits existentes. Em ambos os países o que se discute atualmente é a necessidade de formar professores aptos a lidar com a diversidade em sala de aula, de modo que possam pensar sobre ela náo como um obstáculo, mas como um possível aliado no processo de construção do ensino.

\section{Conclusáo}

Como se nota, a inclusão proporciona uma visão mais arrojada de escola, ensino e educação. Com isto torna-se indispensável a valorização da formação de professores, assim como melhores condiçóes de trabalho e salários dignos, em face do papel político e social que representam estes profissionais. Entretanto, cabe lembrar que a inclusão escolar é uma orientação que diz respeito à escola em sua totalidade, e não apenas ao professor na sala de aula. A educação inclusiva deve ser compreendida para além dos limites escolares. É um conceito social, que propõe a modificação do modo de organização escolar, priorizando a diversidade.

Tanto Brasil como Itália ainda têm pela frente grandes desafios a serem superados para garantir a inclusão escolar com qualidade e a formação docente, que em nosso país ainda carece de diretrizes mais específicas, certamente é um pilar fundamental dentro desta premissa. Porém, é preciso destacar que não é a simples replicação de modelos adotados em outros países que trará os frutos esperados, já que existem diversas particularidades geográficas e culturais que precisam ser observadas. $\mathrm{O}$ que cabe, no entanto, é o estudo mais atencioso de modelos que já demonstraram bons resultados em países nos quais a inclusão escolar é discutida e implementada há muito mais tempo.

O cenário descrito mostra que muitas são as necessidades e que, mais do que uma responsabilidade isolada, o movimento de inclusão deve ser tarefa dos órgãos governamentais e 
das escolas, mas com a participação e mobilização da comunidade, das famílias e das organizaçôes não governamentais. As mudanças necessárias precisam ser graduais e contínuas para que possam ser exequíveis, porém devem ter início imediato para que se possa falar em inclusão com responsabilidade. Ressalta-se que a inclusão de alunos com necessidades educacionais especiais representa um dos desafios mais importantes para a escola e para a sociedade, um espaço no qual são medidas não apenas as dimensões ético-pedagógicas e sociais, mas também políticas. A inclusão pode, dessa forma, ser compreendida como um ato de democracia, no sentido mais amplo e nobre da palavra, constituindo-se um sinal fundamental e igualdade de direitos e oportunidades.

\section{REFERÊNCIAS}

AGÊNCIA EUROPEIA PARA O DESENVOLVIMENTO DA EDUCAÇÃO ESPECIAL.

Princípios-Chave para a Promoção da Qualidade na Educação Inclusiva. Brussels, European Agency, 2009.

BAPTISTA, C. R. Educação Inclusiva. Ponto de Vista, Florianópolis, n.3/4, p.161-172, 2002.

BAUMEL, R. C. R. C. Formação de professores: aportes multiculturais e o movimento da inclusão. Educar, Curitiba, n.24, p.149-161, 2004.

BAUMEL, R. C. R. C.; CASTRO, A.M. Formação de professores e a escola inclusiva - questôes atuais. Integração, Brasília, v.14, n.24, p.6-11, 2002.

BRASIL. Lei de diretrizes e bases da educação. Brasília, Imprensa Oficial, 1996.

. Plano Nacional de Educação. Brasília, Imprensa Oficial, 2001a.

. Decreto 3956. Brasília, Imprensa Oficial, 2001 b.

. Diretrizes Nacionais para a Educação Especial na Educação Básica. Brasília, Imprensa Oficial, 2001c.

. Lei 10.436 - Lei de Libras. Brasília, Imprensa Oficial, 2002.

. Plano Nacional de Formação dos Professores da Educação Básica - PARFOR. Brasília: Imprensa Oficial, 2009.

CABRAL, L. S. A. A legislação brasileira e italiana sobre educação especial-da década de 1970 aos dias atuais. 2010. 139f. Dissertação (Mestrado) - Universidade Federal de São Carlos, São Carlos, 2010.

CANEVARO, A.; GAUDREAU, J. L'educazione degli handicappati - dai primi tentativi alla pedagogia moderna. Roma, Carocci, 1988.

CNE - Conselho Nacional de Educação. Diretrizes Curriculares Nacionais para a Formação de Professores na Educação Básica. Brasília, Imprensa Oficial, 2002.

CORREIA, L.N. Alunos com necessidades educativas especiais nas classes regulares. Porto: Porto, 1997.

D’ALONZO, L.; IANES, D. L'integrazione scolastica dal 1977 al 2007: i primi risultati di una ricerca attraverso lo sguardo delle famiglie. In: CANEVARO, A. L'integrazione scolastica degli alunni con disabilità - trent’anni di inclusione nella scuola italiana. Gardolo, Edizioni Erickson, 2007.

DE ANNA, L. Pedagogia speciale - i bisogni educativi speciali. Milano, Guerini Studio, 2002. 
. Riflessioni sulla Conferenza internazionale "Le Buone prassi per l'integrazione e l'inclusione". L'integrazione scolastica e sociale, v.4, n.2, p.9-26, 2007.

GELATI, M. Pedagogia speciale e integrazione - dal pregiudizio agli interventi educativi. Carocci editore, Roma, 2004.

INEP - Instituto Nacional de Estudos e Pesquisas Educacionais. Censo Escolar 2012. Disponível em http//: www.inep.gov.br. Acesso 12/03/2013.

ITALIA. Consituzione della Repubblica Italiana. Roma, 1947.

MANTOAN, M. E. A hora e a vez da educação inclusiva. Educação e família - Deficiências: a diversidade faz parte da vida. São Paulo, v.1, p.42-45, 2003.

MAZZOTA, M. J. S. Educação especial no Brasil: história e políticas públicas. São Paulo: Cortez, 2003.

MEC - Ministério da Educação. Portaria 3284. Brasília, Imprensa Oficial, 2003.

MEC - Ministério da Educação. Política Nacional de Educação Especial na Perspectiva da Educação Inclusiva. Brasília, Imprensa Oficial, 2007.

MEC - Ministério da Educação. Resolução 004. Brasília, Imprensa Oficial, 2009

MEC Ministério da Educação. Plano Nacional dos Direitos da Pessoa com Deficiência - Viver sem Limite. Brasília, Imprensa Oficial, 2011.

MEC Ministério da Educação. Programa escola acessivel manual do programa escola acessivel. Brasília, Imprensa Oficial, 2012.

MICHELS, M.H. Gestão, formação docente e inclusão: eixos da reforma educacional brasileira que atribuem contornos à organizaçáo escolar. Revista Brasileira de Educação, Rio de Janeiro, v.11, n.33, 2006.

MITTLER, P. Educação inclusiva: contextos sociais. Porto Alegre: ArtMed, 2003.

MIUR - Ministero dell'istruzione dell'università e della ricerca. D.M. 153. Roma, 1998. D.M. 249. Roma, 2010.

. Strumenti d'Intervento per Alunni com Bisogni Educativi Speciali e Organizzazione Territoriale per l'Inclusione Scolastica. Roma, 2012.

MONTEIRO, A.T.M. Educação inclusiva - um olhar sobre o professor. 2003, 113f. Dissertação

(Mestrado) - Universidade Federal de Minas Gerais, Belo Horizonte, 2003.

RODRIGUES, D. A Educação física perante a educação inclusiva: reflexões conceptuais e metodológicas. Revista da Educaçâo Física da UEM, Maringá, v.14, n.1, p.67-73, 2003.

SANCHES, I.; TEODORO, A. Da integração à inclusão escolar:cruzando perspectivas e conceitos. Revista Lusófona de Educação, Lisboa, v.8, p.63-83, 2006.

SILVA, E.J.C.; LLERENNA JÚNIOR, J.C.; CARDOSO, M.H.C.A. Aspectos históricos do atendimento ao deficiente: da segregação à educação inclusiva. Temas sobre Desenvolvimento, São Paulo, v.11, n.63, p.5-13, 2002.

SOUZA, P.N.P.; SILVA, E.B. Como entender e aplicar a nova LDB. São Paulo: Pioneira Educação, 1997. 
TERRA, R.N.; GOMES, C.G. Inclusão escolar: carências e desafios da formação e atuação profissional. Revista Educaçâo Especial, Santa Maria, v.26, n.45, p.109-124, 2013.

VITALIANO, C.R. Análise da necessidade de preparação pedagógica de professores de cursos de licenciatura para inclusão de alunos com necessidades educacionais especiais. Revista Brasileira de Educação Especial, Marília, v.13, n.3, p.399-414, 2007.

VITALIANO, C.R. ; DALL'ACQUA, M.J.C. Análise das diretrizes curriculares dos cursos de licenciatura em relação à formação de professores para a inclusão de alunos com necessidades especiais. Revista Teias, Rio de Janeiro, v.13, n.27, p.103-121, 2012.

WHO - World Health Organization. International Classification of Functioning, Disability and Health. WHO Family of International Classifications Network, 2001.

Recebido em: 28/05/2013

Reformulado em: 28/08/2013

Aprovado em: 10/09/2013 